\title{
CAN WE IDENTIFY PATIENTS WITH CAROTID OCCLUSION WHO WOULD BENEFIT FROM EC/IC BYPASS? REVIEW
}

\author{
Roman Herziga , Petr Hluštík ${ }^{\mathrm{a}, \mathrm{b}}$, Karel Urbánek ${ }^{\mathrm{a}}$, Miroslav Vaverkac, Stanislav Buřval ${ }^{\mathrm{b}}$, \\ Josef Macháčc, Ivanka Vlachováa , Bohdan Kř̌upka ${ }^{a}$, Andrea Bártkováa , Daniel Šaňák \\ Jan Mareša , Petr Kaňovskýa
}

\author{
${ }^{a}$ Stroke Center of Department of Neurology, Teaching Hospital, Olomouc \\ b Department of Radiology, Teaching Hospital, Olomouc \\ c Department of Neurosurgery, Teaching Hospital, Olomouc, Czech Republic \\ e-mail: herzig.roman@seznam.cz
}

Received: September 9, 2004; Accepted (with revisions): October 15, 2004

Key words: Brain infarction/Carotid occlusion/Recurrent stroke/Cerebral vasomotor reactivity/Motor cortex/Extra-intracranial bypass

Occlusion of the internal carotid artery (CAO) is associated with a high mortality rate and frequent disability in survivors. Even in patients with good clinical recovery there is a high risk of recurrent stroke, mainly in those with impaired cerebral vasomotor reactivity (CVR). Current evidence based therapeutic options for patients with symptomatic $\mathrm{CAO}$ include antithrombotic medication and control of vascular risk factors. For stenosis of the contralateral internal or ipsilateral external carotid artery, endarterectomy or percutaneous transluminal angioplasty may be considered. Ongoing symptoms may cease after tapering antihypertensive medications. Extracranial to intracranial (EC/IC) arterial bypass surgery has been used since 1967 in patients with CAO. However, the international randomized EC/IC Bypass Study (1985) failed to confirm the effectiveness of EC/IC bypass for preventing cerebral ischemia in patients with symptomatic $\mathrm{CAO}$ when compared to those assigned to the best medical care. Nevertheless, the conclusion of the EC/IC Bypass Study has several objections and downfalls. Since then, there has been a revival of interest in cerebral revascularization procedures owing to the substantial progression of surgical techniques and the use of more advanced diagnostic methods. Thus, it has recently been reported that EC/IC bypass surgery can be useful in preventing stroke in patients with hemodynamic compromise. The main problem is to identify the small subgroup of surgical candidates. Presently, single photon emission computed tomography (SPECT), positron emission tomography (PET), transcranial Doppler sonography (TCD), computed tomography (CT) with administration of ${ }^{133} \mathrm{Xe}$, perfusion CT, near infrared spectroscopy (NIRS), and functional magnetic resonance imaging (fMRI) are being used for this purpose.

Cerebrovascular stroke is the third most common cause of death in the majority of developed countries ${ }^{1}$, including in the Czech Republic (CR). Approximately 7,000 men and 10,000 women die of stroke each year in our country ${ }^{2}$. The incidence of cerebrovascular stroke in the CR is two times higher than in Western Europe. Occlusion of the internal carotid artery (ICA) is associated with a high mortality rate and frequent disability in survivors ${ }^{3}$. Even in patients with good clinical recovery there is a high risk of recurrent stroke; the annual risk of stroke in patients with symptomatic carotid artery occlusion (CAO) and impaired cerebral vasomotor reactivity (CVR) is approximately $10-14 \%$ versus $4-6 \%$ in those with preserved $\mathrm{CVR}^{4,5}$.

It has been shown that patients with an increased oxygen extraction fraction (OEF) measured by positron emission tomography (PET) with inhalation of ${ }^{15} \mathrm{O}$-labeled gas and low cerebrovascular reactivity assessed by transcranial Doppler sonography ${ }^{6,7}$ have an increased risk of recurrent ischemic stroke. Current evidence based therapeutic options for patients with symptomatic CAO include antithrombotic medication and control of vascular risk factors. For stenosis of the contralateral internal or ipsilateral external carotid artery (ECA), endarterectomy or percutaneous transluminal angioplasty may be considered. Ongoing symptoms may cease after tapering of antihypertensive medication ${ }^{8}$.

In 1967 the first extracranial to intracranial (EC/ IC) arterial anastomosis was performed ${ }^{9}$. However, the international randomized EC/IC Bypass Study (1985) failed to confirm that EC/IC superficial temporal artery (STA) to middle cerebral artery (MCA) bypass is effective for preventing cerebral ischemia in patients with symptomatic $\mathrm{CAO}$ when compared to those assigned to the best medical care ${ }^{10}$. Since then, the operation has been largely abandoned worldwide. Nevertheless, several objections and downfalls have been identified in this study, such as inclusion of the wrong patients (included in the study regardless of their clinical state and cerebral blood flow, $\mathrm{CBF})^{11,12}$. During the last 10 years, there has 
been a revival of interest in cerebral revascularization procedures owing to the significant progression of surgical techniques and the use of more advanced diagnostic methods $^{13}$. Some reports show that EC/IC arterial bypass surgery can be useful in preventing stroke in patients with hemodynamic compromise. For example, recent papers have reported that the supplementary activation of cerebral hemodynamics with EC/IC bypass increases regional $\mathrm{CBF}$ and regional cerebral oxygen metabolism $\left(\mathrm{rCMRO}_{2}\right)$, maintaining adequate cerebral blood oxygenation (CBO) $)^{14-19}$ and it can even alleviate impaired cognition in stroke patients ${ }^{20}$. Derdeyn et al. demonstrated the cost-effectiveness of EC/IC bypass in patients with symptomatic CAO with increased $\mathrm{OEF}^{12}$.

Various kinds of reconstructive operation for both high-grade and low-grade EC/IC bypasses are available. While superficial temporal artery (STA) is the standard donor vessel in both cases, the distal part of the ICA or $M_{1}$ segment of the MCA in high-flow EC/IC bypass, or the $2^{\text {nd }}$ or the $3^{\text {rd }}$ degree MCA branches in low-flow EC/IC bypasses can serve as recipient arteries ${ }^{15}$, 21 . High-flow EC/ IC bypass can establish a larger (up to 3.7-times) increase of blood flow than the low-flow one ${ }^{22}$. Nevertheless, this type of bypass may be associated with a higher risk of cerebral hemorrhage.

One of the main problems for EC/IC bypass is to identify a small subgroup of patients with "hemodynamic" cerebral ischemia. Characteristically, these patients demonstrate a severely impaired cerebrovascular reserve capacity due to occlusive disease and an insufficient collateral blood supply. Besides PET, other methods such as computed tomography (CT) with administration of ${ }^{133} \mathrm{Xe},{ }^{23}$ perfusion $\mathrm{CT},{ }^{24}$ single photon emission computed tomography (SPECT) and near infrared spectroscopy (NIRS) are being used to assess CVR and thus identify patients who could benefit from EC/IC bypass surgery. For example, SPECT, ${ }^{133} \mathrm{Xe}$ inhalation, acetazolamide (ACT) administration ${ }^{25}$, as well as the technique of benzodiazepine receptor SPECT (BZR- SPECT) with ${ }^{123}$ I-iomazenil ${ }^{26}$ have been useful in assessing possible candidate patients. In patients with occlusion of both ICAs, the same techniques may be used also for selection of the appropriate side suitable for the establishment of EC/IC bypass.

Transcranial Doppler sonography (TCD) has also become widely used in assessing CVR by providing information regarding cerebral autoregulation and collateral circulation. Cerebral vasomotor reactivity is defined as a shift between CBF or cerebral blood velocity before and after the administration of a potent vasodilatory stimulus test, such as the apnea test (dilatatory response of CBF to hypercapnia.) This breath-holding maneuver enables assessment of CVR by means of calculating the breathholding index $(\mathrm{BHI})$. The apnea test can be replaced by inhalation of $5 \% \mathrm{CO}_{2}$. Breath-holding has the advantage that it is more rapid and better tolerated than $\mathrm{CO}_{2}$ inhalation, but the reproducibility is lower with breath-holding. Intravenous (i.v.) ACT administration can be also used as a vasodilatory stimulus for TCD assessment of CVR. The main technical problem is the non-existence of a standardized examination procotol in both $\mathrm{CO}_{2}$ inhalation and ACT administration (in the latter case, the route of administration using i.v. injection or infusion, the total dose dependent/non-dependent on body weight and monitoring interval are unclear). The breath-holding/hyperventilation test is a combined test being used for the assessment of CVR during hyper- and hypocapnia ${ }^{27-32}$. The assessment of CVR by combining TCD and provocative vasodilatory tests allows the intracranial hemodynamic status to be evaluated in patients with CAO. It is intended to predict the occurrence of ischemic brain events, compare intracranial hemodynamics before and after EC/IC bypass and autoregulation, measure collateral circulation in the different parts of the circle of Willis, and also predict dementia after stroke ${ }^{33}$.

Used together in a complementary protocol, CVR testing with TCD and cortical assessment with PET can evaluate both the vasodynamics in major vessels, microvascular cortical perfusion, and OEF. The disadvantages of PET is that it is not widely available and theexamination carries a radiation load.

Alternative noninvasive hemodynamic imaging can be performed with functional magnetic resonance imaging (fMRI), a more recently developed method utilizing mostly blood oxygenation level dependent (BOLD) contrast. BOLD fMRI can be accomplished on a typical 1.5 Tesla scanner, available in all regional and university hospitals that perform neurovascular surgery. Functional MRI has been used worldwide to visualize the cortical networks participating in behavioral control and cognitive processing in healthy subjects as well as in patients with cerebrovascular and brain disease. It allows higher spatial resolution than PET and also permits longitudinal studies without a cumulative radiation load. Functional MRI studies in cerebrovascular diseases have typically mapped movement-activated areas in stroke patients recovering motor function by comparing them to motor activation patterns in healthy controls. These studies replicated and extended PET findings by demonstrating differences between patients and controls in multiple brain areas including cortical $^{34-43}$, subcortical, and cerebellar regions ${ }^{41}$. Longitudinal fMRI studies can also reveal motor system changes associated with successful motor recovery ${ }^{40}$ and rehabilitation. Functional MRI has further been used to detect the cortical hemodynamic impact of large-vessel disease, such as asymptomatic carotid stenosis ${ }^{44}$. This study reported slowing and diminution of the cortical hemodynamic response in the hemisphere ipsilateral to carotid stenosis. The same technique was also recently used to assess the CVR in patients suffering from unilateral common carotid artery occlusion and with a patent ECA and $\mathrm{ICA}^{45}$. However, it is not known whether fMRI can replace PET in complementing CVR testing with TCD and ultimately help select patients who will benefit from surgical restoration of major vascular flow by EC/IC bypass.

In summary, it is believed that EC/IC bypass surgery can provide significant benefit to selected patients with 
atherosclerotic arterial disease of the ICAs and MCAs. However, the selection of patients who would likely benefit from the procedure is still questionable. Several patient selection and procedural problems are evident and include the availability of PET examination, the radiation load involved in both SPECT and PET examinations, and acetazolamide availability (not available in some countries, e.g. in the Czech Republic.) Additionally, no standardized protocols exist for the TCD evaluation of CVR using ACT administration and $\mathrm{CO}_{2}$ inhalation. Furthermore, the effectiveness of high- and low-flow EC/IC bypasses has not yet been sufficiently compared. Thus, further studies are needed both in the field of CVR testing and assessing the effects of EC/IC bypass.

\section{ACKNOWLEDGEMENT}

Supported by the IGA Ministry of Health CR grant number NR/7830-3/2004.

\section{REFERENCES}

1. Tegos TJ, Kalodiki E, Daskalopoulou SS, Nicolaides AN. (2000) Stroke: epidemiology, clinical picture, and risk factors - Part I of III. Angiology 51, 793-808.

2. ÚZIS ČR. Zemřelí v České republice v roce 2000. Praha: ÚZIS ČR, 2001.

3. Paciaroni M, Mazzotta G, Caso V, Venti M, Milia P, Silvestrelli G, Palmerini F, Acciarresi M, Parnetti L, Gallai V. (2004) Short and long-term follow-up of patients with stroke due to internal carotid artery occlusion [abstract]. Cerebrovasc Dis 17(Suppl 5), 51-2.

4. Klijn CJ, Kappelle LJ, Tulleken CA, van Gijn J. (1997) Symptomatic carotid artery occlusion. A reappraisal of hemodynamic factors. Stroke 28, 2084-93.

5. Vernieri F, Pasqualetti P, Passarelli F, Rossini PM, Silvestrini M. (1999) Outcome of carotid artery occlusion is predicted by cerebrovascular reactivity. Stroke 30, 593-8.

6. Widder B. (1989) The Doppler CO2 test to exclude patients not in need of extracranial/intracranial bypass surgery. J Neurol Neurosurg Psychiatry 52, 38-42.

7. Karnik R, Valentin A, Ammerer HP, Donath P, Slany J. (1992) Evaluation of vasomotor reactivity by transcranial Doppler and acetazolamide test before and after extracranial-intracranial bypass in patients with internal carotid artery occlusion. Stroke 23, 812-7.

8. Kappelle LJ, Klijn CJ, Tulleken CA. (2002) Management of patients with symptomatic carotid artery occlusion. Clin Exp Hypertens 24, 631-7.

9. Hopkins M, Valberg BM, Robinson LM. (1986) A report on the EC/IC bypass study. J Neurosci Nurs 18, 211-3.

10. The EC/IC Bypass Study Group. (1985) Failure of extracranialintracranial arterial bypass to reduce the risk of ischemic stroke. Results of an international randomized trial. N Engl J Med 313, 1191-200.

11. Ausman JI, Diaz FG. (1986) Critique of the extracranial-intracranial bypass study. Surg Neurol 26, 218-21.

12. Derdeyn CP, Gage BF, Grubb RL Jr, Powers WJ. (2000) Cost-effectiveness analysis of therapy for symptomatic carotid occlusion PET screening before selective extracranial-to-intracranial bypass versus medical treatment. J Nucl Med 41, 800-7.

13. Streefkerk HJ, Van der Zwan A, Verdaasdonk RM, Beck HJ, Tulleken CA. (2003) Cerebral revascularization. Adv Tech Stand Neurosurg 28, 145-225.
14. Takagi Y, Hashimoto N, Iwama T, Hayashida K. (1997) Improvement of oxygen metabolic reserve after extracranial-intracranial bypass surgery in patients with severe haemodynamic insufficiency. Acta Neurochir (Wien) 139, 52-6.

15. Klijn CJ, Kappelle LJ, van der Grond J, van Gijn J, Tulleken CA. (1998) A new type of extracranial/intracranial bypass for recurrent haemodynamic transient ischaemic attacks. Cerebrovasc Dis 8 , 184-7.

16. Ishikawa T, Kuroda S, Hokin K, Kamiyama H, Abe H. (1998) [Can EC-IC bypass prevent brain ischemia from recurring?] No Shinkei Geka 26, 823-9.

17. Fischer B, Palkovic S, Wassmann H. (2002) Worsening in ischemic stroke patients: supplementary activation of cerebral hemodynamic with EC/IC bypass. Stroke 33, 2734.

18. Murata Y, Katayama Y, Sakatani K, Fukaya C, Kano T. (2003) Evaluation of extracranial-intracranial arterial bypass function by using near-infrared spectroscopy. J Neurosurg 99, 304-10.

19. Neff KW, Horn P, Dinter D, Vajkoczy P, Schmiedek P, Duber C. (2004) Extracranial-intracranial arterial bypass surgery improves total brain blood supply in selected symptomatic patients with unilateral internal carotid artery occlusion and insufficient collateralization. Neuroradiology, 46, 730-7.

20. Sasoh M, Ogasawara K, Kuroda K, Okuguchi T, Terasaki K, Yamadate K, Ogawa A. (2003) Effects of EC-IC bypass surgery on cognitive impairment in patients with hemodynamic cerebral ischemia. Surg Neurol 59, 455-60.

21. Klijn CJ, Kappelle LJ, van der Zwan A, van Gijn J, Tulleken CA. (2002) Excimer laser-assisted high-flow extracranial/intracranial bypass in patients with symptomatic carotid artery occlusion at high risk of recurrent cerebral ischemia: safety and long-term outcome. Stroke 33, 2451-8.

22. van der Zwan A, Tulleken CA, Hillen B. (2001) Flow quantification of the non-occlusive excimer laser-assisted EC-IC bypass. Acta Neurochir (Wien) 143, 647-54.

23. Yamashita T, Kashiwagi S, Nakano S, Takasago T, Abiko S, Shiroyama Y, Hayashi M, Ito H. (1991) The effect of EC-IC bypass surgery on resting cerebral blood flow and cerebrovascular reserve capacity studied with stable XE-CT and acetazolamide test. Neuroradiology $33,217-22$.

24. Ferda J. CT angiografie. Praha: Galén, 2004.

25. Schmiedek P, Piepgras A, Leinsinger G, Kirsch CM, Einhupl K. (1994) Improvement of cerebrovascular reserve capacity by EC-IC arterial bypass surgery in patients with ICA occlusion and hemodynamic cerebral ischemia. J Neurosurg 81, 236-44.

26. Makino K, Kamiyama H, Takamura H, Gotoh S, Kobayashi N. (1999) Assessment of outcome by EC/IC bypass with ${ }^{123}$ I-iomazenil brain SPECT. Ann Nucl Med 13, 261-4.

27. Umemura A, Yamada K, Masago A, Kanda Y, Matsumoto T, Shimazu N. (2002) Hemodynamic flow patterns evaluated by transcranial color-coded duplex sonography after STA-MCA bypass for internal carotid artery occlusion. Cerebrovasc Dis 14, 143-7.

28. Vernieri F, Pasqualetti P, Matteis M, Passarelli F, Troisi E, Rossini PM, Caltagirone C, Silvestrini M. (2001) Effect of collateral blood flow and cerebral vasomotor reactivity on the outcome of carotid artery occlusion. Stroke 32, 1552-8.

29. Muller M, Voges M, Piepgras U, Schimrigk K. (1995) Assessment of cerebral vasomotor reactivity by transcranial Doppler ultrasound and breath-holding: A comparison with acetazolamide as vasodilatory stimulus. Stroke 26, 96-100.

30. Ringelstein EB, Van Eyck S, Mertens I. (1992) Evaluation of cerebral vasomotor reactivity by various vasodilating stimuli: comparison of $\mathrm{CO}_{2}$ to acetazolamide. J Cereb Blood Flow Metab 12, $162-8$.

31. Ringelstein EB, Sievers C, Ecker S, Schneider PA, Otis SM. (1988) Noninvasive assessment of $\mathrm{CO}_{2}$-induced cerebral vasomotor response in normal individuals and patients with internal carotid artery occlusions. Stroke 19, 963-9.

32. Totaro R, Marini C, Baldassarre M, Carolei A. (1999) Cerebrovascular reactivity evaluated by transcranial Doppler: reproducibility of different methods. Cerebrovasc Dis 9, 142-5. 
33. Gur AY, Bornstein NM. (2001) TCD and the Diamox test for testing vasomotor reactivity: clinical significance. Neurol Neurochir Pol 35 Suppl 3, 51-6.

34. Cramer SC, Nelles G, Benson RR, Kaplan JD, Parker RA, Kwong KK, Kennedy DN, Finklestein SP, Rosen BR. (1997) A functional MRI study of subjects recovered from hemiparetic stroke. Stroke 28, 2518-27.

35. Seitz RJ, Hoflich P, Binkofski F, Tellmann L, Herzog H, Freund HJ. (1998) Role of the premotor cortex in recovery from middle cerebral artery infarction. Arch Neurol 55, 1081-8.

36. Cao Y, D‘Olhaberriague L, Vikingstad EM, Levine SR, Welch KM. (1998) Pilot study of functional MRI to assess cerebral activation of motor function after poststroke hemiparesis. Stroke 29 112-22.

37. Marshall RS, Perera GM, Lazar RM, Krakauer JW, Constantine RC, DeLaPaz RL. (2000) Evolution of cortical activation during recovery from corticospinal tract infarction. Stroke 31, 656-61.

38. Hlustik P, Solodkin A, Gullapalli RP, Noll DC, Small SL. (2001) Somatotopy in human primary motor and somatosensory hand representations revisited. Cereb Cortex 11, 312-21.

39. Solodkin A, Hlustik P, Noll DC, Small SL. (2001) Lateralization of motor circuits and handedness during finger movements. Eur $\mathrm{J}$ Neurol 8, 425-34.
40. Pineiro R, Pendlebury S, Johansen-Berg H, Matthews PM. (2001) Functional MRI detects posterior shifts in primary sensorimotor cortex activation after stroke: evidence of local adaptive reorganization? Stroke 32, 1134-9.

41. Small SL, Hlustik P, Noll DC, Genovese C, Solodkin A. (2002) Cerebellar hemispheric activation ipsilateral to the paretic hand correlates with functional recovery after stroke. Brain $125,1544-$ 57.

42. Hlustik P, Solodkin A, Gullapalli RP, Noll DC, Small SL. (2002) Functional lateralization of the human premotor cortex during sequential movements. Brain Cogn 49, 54-62.

43. Hlustik P, Solodkin A, Small SL. (2002) Cortical plasticity during three-week motor skill learning [abstract]. Neurology 58(Suppl 3), A265.

44. Carusone LM, Srinivasan J, Gitelman DR, Mesulam MM, Parrish TB. (2002) Hemodynamic response changes in cerebrovascular disease: implications for functional MR imaging. Am J Neuroradiol 23, 1222-8.

45. Herzig R, Hlustik P, Urbanek K, Nekula J. (2004) fMRI of the motor cortex in a patient suffering from unilateral common carotid artery occlusion and with patency of external and internal carotid arteries [abstract]. Eur J Neurol 11(Suppl 2), 176. 